\title{
A Comprehensive Study of Electricity Consumption of People in Each Region in the Philippines
}

\author{
Renz Chester Rosales Gumaru ${ }^{1,}$, Renren Banta ${ }^{2}$ \\ ${ }^{1}$ Math Department, Arellano University, Pasay, Philippines \\ ${ }^{2}$ Math Department, Alabang High School, Alabang, Philippines \\ Email address: \\ renzchestergumarubsmath $a$ gmail.com (R. C. R. Gumaru), renrenbanta@gmail.com (R. Banta) \\ ${ }^{*}$ Corresponding author
}

\section{To cite this article:}

Renz Chester Rosales Gumaru, Renren Banta. A Comprehensive Study of Electricity Consumption of People in Each Region in the Philippines. American Journal of Mechanics and Applications. Vol. 7, No. 3, 2019, pp. 45-48. doi: 10.11648/j.ajma.20190703.12

Received: May 26, 2019; Accepted: August 22, 2019; Published: September 5, 2019

\begin{abstract}
Electricity is one of the most important source of energy in our everyday lives. We use it every day in different situations and circumstances. However, it is also the most used and most expensive energy that we always use. This study will determine which region in the Philippines consumed the most and least electricity. It will also study the relationship between the different distributor of electricity and electricity consumption. This study will help the society in solving the problem of dealing will high cost of electricity. Knowing which regions are the most and least consuming in terms of electricity will surely help the government identify why that particular regions consume a lot, or consume less. This study will also determine if there are changes every month in the most and least consuming electricity regions. The researchers also explore different and various problems and factors contributing to the consumption of electricity of each region in the Philippines. And the researchers also seek if there is a significant difference in the consumption of electricity between regions in the National Capital Region, and I $n$ province. This study will surely help and contribute a lot to a developing country like the Philippines, especially the country is known for consumption of too much electricity.
\end{abstract}

Keywords: Electricity, Energy, Philippines, Source, Power

\section{Introduction}

\subsection{Objectives of the Study}

The objective of this study is to know the electricity consumption of the Filipinos in each region. This study aims to know which region consume the most electricity in the Philippines. We know that electricity is one thing in our life that we use every day. It is one of the main problems of the Philippines due to its consistent raising price.

Knowing which regions are the most and least consuming in terms of electricity will surely help the government identify why that particular regions consume a lot, or consume less. This study will also determine if there are changes every month in the most and least consuming electricity regions.

This study will also know the factors why a particular region needed to consume more or less electricity. It will discuss the different factors that can affect the usual consumption. Lastly, it will help the society in limiting the use of very expensive electricity.

\subsection{Theoretical Framework}

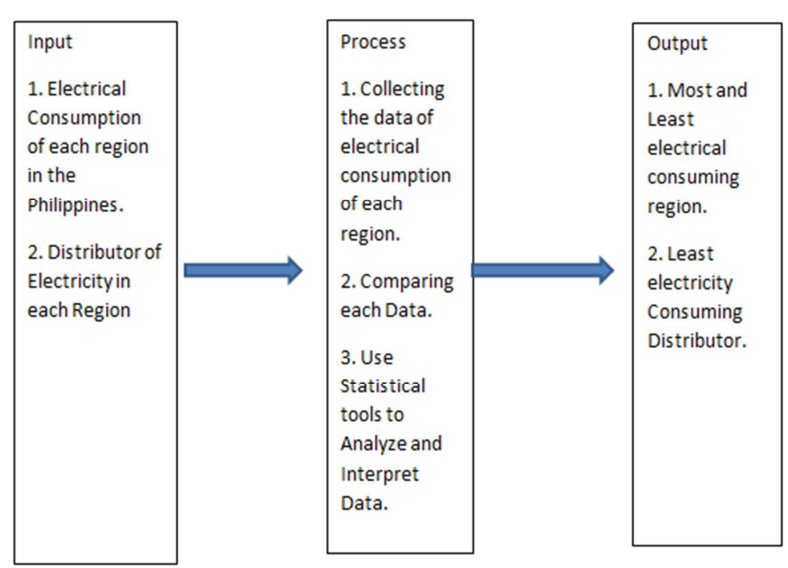

Figure 1. Theoretical Framework. 


\subsection{Conceptual Framework}

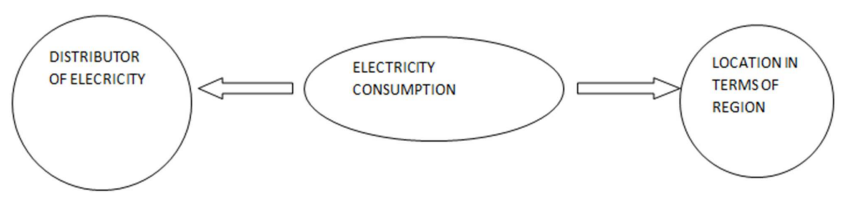

Figure 2. Conceptual Framework.

\subsection{Statement of the Problem}

Is There a Relationship Between the Electricity Consumption of Filipinos and the ff:

Location by Region.

\subsection{Scope and Limitations of Study}

The scope and limitation of this study is only from January 2015 to January 2018. It only studies the electricity consumption of each region from the year 2015 -2018. It is also only applicable in our country which is the Philippines.

\subsection{Significance of the Study}

The significance of this study is to help the society in suffering due to the expensive cost of electricity. It will also determine why a particular region needed to use more electricity than the others. It will also determine the factors that affect the electricity consumption.

\subsection{Review Literatures and Studies}

Gross domestic product (GDP), employment rates, residential space, and the implementation of energy labeling schemes provide significant impacts on residential electricity consumption. However, the impacts of electricity price and the energy efficiency standards do not receive significant support. The analysis of the direct use approach finds that air conditioners consume the largest portion of electricity, amounting to $1470 \mathrm{kWh}$ for each household and accounting for $26.81 \%$ except for lighting. Refrigerators and rice cookers follow, consuming $815.83 \mathrm{kWh}(14.88 \%)$ and $343.85 \mathrm{kWh}$ $(6.27 \%)$ of electricity. [1]

The emergence of the smart grid, smart meters and smart appliances provide consumers of electricity with new means to observe their energy consumption more closely and to have the option to change their consumption habits to improve on their savings. With increased awareness of the possibilities of decreasing electricity consumption and the possibility of saving money on their electricity bill residents of existing homes should be looking for solutions. [2]

The uncertainty of electricity demand is an important risk factor for customers as well as for utilities and retailers. As a consequence, forecasting electricity load and its risk is now an integral component of the risk management for all market participants. [3]

Electricity plays a pivotal role in nation building. With it, various sources of livelihood are created, delivery of services is improved which leads to the betterment of the lives of people. In recent years, technology has revolutionized the electricity sector. The outstanding performance of the economy demonstrated the importance of electricity to economic expansion. No doubt, electricity is an essential input to all economic activities. [4]

It has been observed that many power utilities, especially in developing countries, have neither developed nor implemented DSM for their electrical energy management. This paper proposes that the existing PFC techniques should be re-evaluated especially when loads are nonlinear. It also recommends automatic demand control methods to be used on the demand side in order to acquire optimal energy consumption. This would lead to improved reliability of the supply side and thereby reducing environmental degradation. [5]

The research findings showed that the households in the province already observed electrical energy conservation measures primarily to lessen electrical bill/cut down on expenses. There are, however, considerable potentials for more efficient electrical energy utilization practices among such households based on the proportion of the households which do not yet practice conservation measures, namely scheduling of appliance use $(100 \%)$, not overheating/overcooling rooms $(84.9 \%)$, scheduling home energy audit $(84.7 \%)$, selecting energy efficient appliances $(84.4 \%)$, scheduling computer games only on weekends $(76.9 \%)$, air dying of clothes instead of electrical drying $(66.2 \%)$, using electric fans only when people are around $(63.8 \%)$ and using fluorescent lamps instead of incandescent lamps (55.8\%). [6]

Electricity consumption in the Philippines increased to 94,370 gigawatt hours (GWh) in 2017, the Department of Energy (DoE) said. Power use in Luzon rose 3.58 percent to 69,625 GWh from $67,221 \mathrm{GWh}$; Visayas, up 5.8 percent to 12,942 GWh from 12,232 GWh; and Mindanao, up 4.04 percent to $11,804 \mathrm{GWh}$ from $11,345 \mathrm{GWh}$. [7]

Based on the results of the 2011 Household Energy Consumption Survey (HECS), electricity remains as the most common source of energy used by households in the Philippines. About 87 percent of 21.0 million households used electricity from March to August 2011. The other sources used by a significant proportion of households include fuelwood, charcoal, LPG and kerosene with at least one-third of the total households using any of these types of fuel in 2011. [8]

Electricity, which is usually used for lighting, is consumed at 58.33 billion kilowatt-hours. Aside from lighting, electricity is also used for telecommunications and transportation. But despite seemingly high demand in the electricity market, its consumption lowered from last year's 61.31 billion kilowatt-hours. [9]

This entry consists of total electricity generated annually plus imports and minus exports, expressed in kilowatt-hours. The discrepancy between the amount of electricity generated and/or imported and the amount consumed and/or exported is accounted for as loss in transmission and distribution. Electricity - consumption: 74.15 billion kWh (2016 est.) [10]

Energy consumption in the country is affected by weather 
deviations and gender, according to a study published by state think tank Philippine Institute for Development Studies (PIDS). In the Philippines, very few have analyzed energy use within the context of both weather variability and gender. Senior Research Fellow Connie Bayudan-Dacuycuy's policy note titled "Examining Energy Use and Weather Variability through the Gender Lens" aimed to analyze how energy consumption in households vary depending on the dominant gender in the household and weather fluctuations in an area. [11]

Electricity prices in Metro Manila (MM) are the third highest among fourteen major cities in North and Southeast Asia plus Australia and New Zealand in January 2013 - third in overall residential tariff, third in generation cost, third in grid charges, and third in tax rates (The Lantau Group HK Limited 2013). Given tight budget allocations for campus operations and maintenance, higher education institutions (HEIs) are increasingly pressured to predetermine accurately the energy cost of running their academic buildings and facilities. The accurate programming of the electric demand of a single building can result in considerable savings that may be utilized to provide more and better services to stakeholders while keeping matriculation at highly affordable levels. [12]

An examination of a residential bill in Manila further reveals an energy cost component unique to the Philippines. At least 15 percent of a residential electric bill comprises of miscellaneous charges that represent subsidies for the elderly and marginalized end-consumers, rural electrification, subsidies to incentivize development of renewable energy and the cost of debt incurred by the government in the past. The history of the energy industry in the Philippines reveals that loose implementation policies, especially at the local level, external economic factors such as currency depreciation and increase in interest rates and oil prices, ineffective demand projections and poor pipeline planning as well as political influences led to the massive debt incurred by the government. [13]

Energy switching is observed among high-income urban and rural households, while energy stacking is observed among rural households in response to a heat index deviation and an LPG price shock. The paper also finds that households' energy portfolios have components comprising of modern sources as energy anchors and a component that is most likely to adjust in response to price and weather-related shocks. [14]

It is the final consumer who ultimately shoulders three costs: distribution, transmission, and power generation. What he pays are reflected in the electricity price index. Based on the Philippine Statistical Authority (PSA) survey, 4.800195\% or more than $1 / 25$ of all household expenditures in the Philippines go to electricity. [15]

Despite the country having the second most expensive power in Asia following Japan, most Filipinos used electricity as their main source of energy in their household, according to a 2011 data from the National Statistics Office (NSO). In a statement on Friday, NSO Administrator Carmelita Ericta and Energy Secretary Carlos Jericho Petilla said that most of the Filipino families use electricity as their main source of home power for 2004 and 2011. "About 87 percent of 21 million households used electricity from March to August 2011," the two executives said, basing on the 2011 Household Energy Consumption Survey (HECS) by the NSO. (16)

\section{Methods}

The Methodology that the researchers used in this study are collecting, analyzing, and interpreting data. The researchers also used some statistical tools or treatment to help in analyzing and interpreting the given data.

\section{Results}

Table 1. Yearly Electricity Consumption of each Region in the Philippines from 2015-2018.

\begin{tabular}{ll}
\hline Regions & Total Consumed Electricity (2015-2018) \\
\hline 1 & $132,044,701$ \\
2 & $49,986,553,259$ \\
3 & $16,254,514,423$ \\
$4 \mathrm{a}$ & $4,958,007,296$ \\
$4 \mathrm{~b}$ & $2,321,948,198$ \\
5 & $4,189,952,246$ \\
6 & $8,710,318,430$ \\
7 & $13,465,397,578$ \\
8 & $2,918,567,075$ \\
9 & $3,657,390,656$ \\
10 & $5,721,284,746$ \\
11 & $7,082,733,594$ \\
12 & $4,998,167,230$ \\
ARMM & $2,965,494,250$ \\
CARAGA & $287,102,013$ \\
TOTAL & $127,649,475,695$ \\
\hline
\end{tabular}

\section{Discussion}

Table 1 shows that Region 2 consumed the most electricity in the Philippines, while CARAGA consumed the least electricity. It is also noticeable that urban areas or regions consumes more electrical energy than rural areas. This implies that there is a significant difference between the used of electricity in each region. Every region have their own neccesities on the use of electricity. Consequently, it is expected to have different number of consumed electricity in each region.

\section{Conclusion}

Based on the results of our data, the following conclusion are made:

1. The regions in the province consume less electricity than those regions in commercial areas.

2. There is a significant difference between the electricity consumption between each region of the Philippines.

3. All regions use electricity but differs on the number of consuming the product due to the fact that they have different necessities. 


\section{References}

[1] Yu Tui Chen, The Factors affecting the Electricity Consumption and the Consumption Characteristics in the Residential Sector, (2017).

[2] Björg Sigurjónsdóttir, Monitoring and Reducing the Consumption of Home Electric Appliances, (2013).

[3] Berk. Kevin, Modelling and Forecasting Electricity Demand, (2012).

[4] NTRC Tax Research Journal Volume XXIII, A Review of Electrical Energy Management Techniques and Consumer Side, (2011).

[5] Mohamed Tariq Khan, Philippines: household electricity consumption for capita, (2015).

[6] Eddie Seva See (2010), Electric Energy Utilization on the Household of Albay province, (2012).

[7] JORDEENE B. LAGARE, PH Power Consumption up nearly $4 \%$ Cost Last Year, (2018).
[8] https://psa.gov.ph/tags/energy-consumption), Consumption in the Philippines, (2011).

[9] Jane Moraleda, Energy consumption in the Philippines, (2015).

[10] https://www.indexmundi.com/philippines/electricity_consump tion.html, Philippines Electricity Consumption Energy, (2016).

[11] https://pids.gov.ph/press-releases/325, weather, gender, affect household enebry Consumption, (2013).

[12] Maureen Anne Araneta1, Cost- effective Programming of electric Demand in U. P Diliman (2017).

[13] Uy, Frances Irene, Energy Pricing in the Philippines and its effect in Economic Growth, (2016).

[14] Connie Bayudan-Dacuycuy Lawrence B. Dacuycuy, Urban and Rural Household's energy use in the Philippines, (2018).

[15] Antonio A. Ver, Electricity most used Household Power Source, (2019).

[16] KRISTYN NIKA M. LAZO, Philippines: Energy sector Assessment, (2013). 